\title{
Productive Safety Net Program and Dietary Practice Among Pregnant Women in Kacha Birra District, Southwest Ethiopia: Comparative Cross-Sectional Study
}

LEMLEM DANIEL BAFFA ( $\nabla$ lemmidan@gmail.com )

University of Gondar https://orcid.org/0000-0002-2291-7755

TEREFE DERSO

University of Gondar

ESMAEL ALI MUHAMMAD

University of Gondar

Research

Keywords: PSNP, dietary practice, pregnant women, Southwest Ethiopia

Posted Date: September 3rd, 2020

DOI: https://doi.org/10.21203/rs.3.rs-65537/v1

License: (9) This work is licensed under a Creative Commons Attribution 4.0 International License.

Read Full License 


\section{Abstract}

Background: Morbidity and mortality associated with poor dietary practice among pregnant women are a common public health burdens especially in low income countries like Ethiopia, for which, household food insecurity can be a determinant factor. Productive safety net program (PSNP) is implemented in Ethiopia to alleviate this problem with emphasis on pregnant and lactating mothers even though little is known about the dietary practice among pregnant women in the program user and non-user households. Therefore, this study is aimed to compare the proportion of good dietary practice and associated factors among pregnant women in productive safety net program user and non-user households in Kacha Birra District.

Method: A Community based comparative cross sectional study was conducted in Kacha Birra District from March 12 to April 20, 2019. A total of 715 pregnant women were included by simple random sampling technique. A pretested and structured interviewer administered questionnaire was used to collect the data. Data was entered into EpiData version 3.1 and transferred to Stata version 14 for analysis. Binary logistic regression model was fitted to identify factors associated with dietary practice. Crude odds ratio and adjusted odds ratios with $95 \%$ confidence intervals were calculated to assess the strength of associations and significance of the identified factors with dietary practice.

Result: The overall proportion of good dietary practice among pregnant women was $14.97 \%$ (95\% Cl: $12.3-$ 17.6), while it was $11.17 \%$ (95\% Cl: 6.5-15.8) and 16.23\% (95\% Cl: 13.09-19.36) among pregnant women in PSNP user and non PSNP user households respectively. Dietary knowledge ( $\mathrm{AOR}=2.64,95 \% \mathrm{Cl}: 1.67-4.18)$, nutrition information ( $\mathrm{AOR}=2.36,95 \% \mathrm{Cl}: 1.41-3.95)$ and husband occupation (AOR=3.51, 95\%Cl:1.0212.08) were significantly associated with dietary practice of the pregnant women.

Conclusion: The proportion of good dietary practice of the pregnant women in the study area was low with no significant difference among the comparative groups. Dietary knowledge, nutrition information and husband occupation were significantly associated with the dietary practice. So, giving due attention to the improvement of knowledge of the pregnant mothers about nutrition during pregnancy and enhancing their exposure to nutrition information is crucial. Also, strengthening the PSNP is important.

\section{Background}

Pregnancy is a state associated with many physiological changes like: increased plasma volume, formation of new fetal tissue, growth of existing maternal tissues and deposit of energy in different tissues of the body. It is associated with increased demand of both macro and micronutrients that makes pregnant women highly vulnerable for malnutrition [1-3].

Globally, the burden of maternal and child under nutrition is very high, affecting hundreds of millions of pregnant women and young children[4]. More specifically, micronutrient deficiency among pregnant women is common across regions and countries of the world. Anemia and vitamin A deficiency affect approximately 32 million and 19 million pregnant women worldwide respectively[5]. Almost $40 \%$ of 
pregnant women in developing countries are anemic[6]. This high burden of maternal under nutrition is more significant in developing countries of south Asia and Sub-Saharan Africa[7]. Maternal under nutrition in Africa also ranges from 5\%-20\%[8].

In Ethiopia, the rate of chronic energy deficiency among women is a significant burden[9], whereas, anemia is detected on $33.6 \%$ of the pregnant women[10]. After all, by a systematic review of studies from the developing countries, inadequate dietary practice during pregnancy has been identified as one of the causes of maternal under nutrition and death during pregnancy[11].

Maternal dietary practice during pregnancy is thought to be one of the factors influencing the health of both the mother and her growing fetus, posing a great burden of morbidity and mortality for both the mother and the fetus[12], abnormal fetal programming so that increasing the future risk of chronic diseases[13], poor birth outcomes[14, 15] and perpetuation of intergenerational cycle of malnutrition[16].

Previous community based studies conducted in Ethiopia showed that, the proportion of good dietary practice ranges from $26.9-40.1 \%[2,15,17,18]$, for which, sociodemographic and economic factors[17], dietary knowledge[15], attitude of the pregnant women for diet[19], exposure to nutrition information[3, $12,15]$ and pregnancy related factors $[2,20]$ were explained as a determinant factors even though their significance shows variation from setting to setting. Also, as explained by WHO report and findings from studies, food insecurity is one of the major determining factors for dietary practice of pregnant women, increasing the burden of fetal and maternal risk[21, 22]. To alleviate this problem, several nutrition specific interventions like: micronutrient, most commonly Iron folate supplementation and supplementary feeding for malnourished pregnant women are undertaken in Ethiopia[23] and showed some improvement in the nutritional status and prevalence of anemia among the pregnant women through time[9]. Along with the nutrition specific interventions, one of the nutrition sensitive interventions, Productive Safety Net Program (PSNP), was started to be implemented to support food insecure HHs living in chronically food insecure areas through public works employment and unconditional transfers with the aim of improving food security status of the households and avoid depleting their productive assets to meet their basic food requirements[24, 25]. The 2015 revised PSNP started to provide temporary direct support and linkage to different social services for pregnant and lactating women in food insecure $\mathrm{HHs}[23]$ to improve their dietary practice and nutritional status as well as their new born child.

However, little is known about the proportion of good dietary practice and factors affecting it among pregnant women in PSNP beneficiary areas. Also, there is information gap, regarding difference in the proportion of good dietary practice of pregnant women in PSNP user and non PSNP user HHs in the country as well as in the district. Therefore, this study was aimed to compare the proportion of the dietary practice of pregnant women in PSNP user and non PSNP user HHs in Kacha Birra District and to identify factors affecting it for further intervention.

\section{Methods}




\section{Study design and setting}

A community based comparative cross sectional study design was conducted from March 12 to April 20, 2019 in Kacha Birra District, one of the administrative districts found in Kembata Tembaro zone, South nation nationalities and peoples region (SNNPR), Southwest Ethiopia. The district covers an area of $1666.724 \mathrm{sq}$. $\mathrm{km}$ and has 21 kebeles. The capital town of the district is Shinshicho town, which is located $293 \mathrm{~km}$ from Addis Ababa, the capital of Ethiopia. The district has 1 primary hospital, 4 health centers and 23 health posts providing services including maternal and child care. The total number of population in the district was 153,677 , of which, 5178 were pregnant women [26].

Households in the area depend both on livestock and crop production. As the crop production is completely rain-fed, the area suffers of a food deficit every year. The district comprises both highland and lowland areas, where the lowland areas are more prone to drought and food insecurity. PSNP was started to be implemented in the district in 2005. All kebeles of the district are beneficiary since the very beginning of the program. Currently, the PSNP in the district is delivered in two modalities; cash is given to households with able bodied members who can repay it by engaging in any developmental activities, like water and soil conservation, road construction, etc. On the other hand, food aid is given to households with no able-bodied members. According to the 2011 district disaster and risk management office early warning and response cluster report,16,563 people of the district were PSNP users[27].

\section{Study population and sampling procedure}

All pregnant women in PSNP user and non PSNP user HHs who had lived at least for six months in the study area were included in the study. As the study was a comparative type, the minimum sample size was determined by using the double population proportion formula that the two groups were classified based on their PSNP beneficiary status. Group one were pregnant mothers from PSNP user HHs, considered as exposed and group two were pregnant mothers from non PSNP user HHs, considered as not exposed. To estimate the minimum sample size, the proportion of good dietary practice $26.9 \%$ was used, which was obtained from previous study conducted in non PSNP user HHs [17]. Since there was no previous study conducted among pregnant women in PSNP user HHs, the proportion of good dietary practice among pregnant women in PSNP user HHs was assumed to be decreased by $15 \%$ from that of non PSNP user HHs, in fact that PSNP user HHs are food insecure and have low access to resources, so that 1 was $11.9 \%$. The final sample size was calculated by using Epi Info software by using $95 \%$ confidence level, $80 \%$ power, ratio of unexposed to exposed $(r)=3$, design effect of 2 , and non-response rate of $10 \%$. The final minimum sample size was 739 . As the ratio of exposed to unexposed used in the study was 1:3, the sample size for the exposed group (n1) was 185 and for the unexposed group (n2) was 554.

Of the total 21 kebeles found in the District, eight kebeles were selected by using simple random sampling (SRS). Then, HHs with pregnant mothers in each selected kebele were stratified based on PSNP beneficiary status. Since there was sampling frame of the pregnant women in the health post of each 
kebele, pregnant women from both PSNP user and non PSNP user HHs of each selected kebele were selected by simple random sampling after proportional allocation of the sample sizes calculated to the two groups to the total number of pregnant mothers in each stratum (users and nonusers) of each selected kebele.

\section{Variables}

Dependent Variable

Dietary practice (poor, good)

Independent variables

- Socio demographic factors

- Pregnancy related characteristics

- Nutrition information during the current pregnancy

- Dietary knowledge of pregnant women

- Attitude about diet of the pregnant women

\section{Operational definitions}

Dietary practice: It is the observable action or behavior of dietary habit of the pregnant mothers at the time of the pregnancy[2].

Good dietary practice: if the pregnant mothers correctly answer $\geq 75 \%$ of the ten questions assessing the dietary practice[2].

Dietary knowledge: It is awareness and understanding that one has gained on nutrition during pregnancy through learning and practice[28].

Good knowledge: if the pregnant mothers correctly answer $\geq 70 \%$ of ten questions assessing their knowledge about diet during pregnancy $[18,28]$.

Attitude: It is the pregnant women's emotion, motivation, perception and thought which influence her eating behavior[19].

Favorable attitude: is when the respondents' attitude score > median[19].

Have nutrition information: if the pregnant mother heard or was advised to have a healthy diet, to eat more and to eat different vegetables and fruits at any time in current pregnancy[29].

Wealth index: It is analyzed by using Principal Component Analysis(PCA) and classified as low, middle and high[30].

\section{Data collection tool and quality control}


Data from the pregnant women were collected through home to home visit using a structured interviewer administered questionnaire. The questionnaire was designed to capture socio-demographic characteristics, health service utilization, pregnancy related characteristics, nutrition information during the current pregnancy, dietary knowledge of pregnant women and attitude about diet of the pregnant women.

The questionnaire was first prepared in English, translated to local language (Kembatgna) and then retranslated back to English to keep consistency. The data was collected by six diploma nurses, who fluently speak both Amharic and the local language (Kembatgna) and two health officers were recruited for the supervision purpose. To maintain the data quality, two days training was given to the data collectors and supervisors and the questionnaire was pre-tested on $5 \%$ of the actual sample size in nonselected Kebele. Frequent and timely supervision of the data collectors was done by the supervisors. Data was monitored and checked for completeness on daily basis by the data collectors as well as by the supervisors and by the Principal investigator (PI) during the data collection. To minimize the social desirability bias, the pregnant women were informed about the objectives of the study in detail and the information they give is handled confidential.

\section{Methods of assessment}

For assessing the dietary practice, ten questions were used and each question was given one mark if the answer was correct and zero score was given if the response was wrong[2,15]. The score was obtained by summation of responses of each question and converted to percentage, then if the respondent answered less than $75 \%$ of the ten questions classified as poor dietary practice. Also for assessing dietary knowledge of the respondents, ten questions were used and each question was given one mark if the answer was correct and zero score was given if the response was wrong[2]. The score was obtained by summation of responses of each question and converted to percentage and then classified as poor dietary knowledge if the respondent answered less than $70 \%$. Dietary attitude was assessed using nine questions obtained from previous study and converted to percentage. Since the data was skewed, median was calculated to consider it as favorable or unfavorable[19] .

\section{Data processing and analysis}

Data was cleaned, coded and entered into EpiData software version 3.1 and transferred to Stata version 14 for further analysis. Descriptive statistics including tables and graphs were done to describe the characteristics of the study participants. Chi-square test was done to detect the presence of statistically significant difference between the comparative groups. A binary logistic regression was fitted to identify factors associated with the dietary practice of the pregnant women. Variables with a p-value of $<0.2$ in bivariable logistic regression were entered to the multivariable logistic regression analysis. Both Crude Odds Ratio (COR) and Adjusted Odds Ratio (AOR) with the corresponding 95\% Confidence Interval (Cl) were calculated to show the strength of association. In multivariable analysis, variables with a $p$-value of $<0.05$ were considered as statistically significant. Hosmer and lemeshow goodness of fit test was done 
to check the adequacy of the model. Wealth index of the respondents in each group was analyzed using PCA.

\section{Result}

\section{Socio demographic characteristics of the study participants}

A total of 715 pregnant women were interviewed with the response rate of $96.8 \%$ from each group, of which, 536 (74.97\%) were from non PSNP user households. Most of the respondents from both groups were in the age group of $25-34$ years $(61.01 \%$ from non PSNP user HHs and $69.83 \%$ from PSNP user $\mathrm{HHs}$ ). More than three quarter of the respondents from both groups were housewives $(74.9 \%$ from PSNP user $\mathrm{HHs}$ and $81.5 \%$ from non PSNP user $\mathrm{HHs}) ; 122(68.15 \%)$ and $376(70.15 \%)$ of the study participants from PSNP user and non PSNP user households had attended primary education (Table 1). 
Table 1

Socio-demographic characteristics of the pregnant women from PSNP user and non PSNP user households of Kacha Birra District, southwest Ethiopia, 2019

\section{Characteristics Pregnant mothers from Pregnant mothers from non Total $(n=715)$ PSNP user HHs $\mathrm{n}=179 \quad$ PSNP user HHs $\mathrm{n}=\mathbf{5 3 6}$}

Frequency Percent Frequency Percent frequency percent

\section{Age of the respondents}

\begin{tabular}{lllllll}
$15-24$ & 50 & 27.93 & 190 & 35.45 & 240 & 33.57 \\
\hline $25-34$ & 125 & 69.83 & 327 & 61.01 & 452 & 63.22 \\
$35-44$ & 4 & 2.24 & 19 & 3.54 & 23 & 3.22
\end{tabular}

\section{Marital status}

$\begin{array}{lllllll}\text { Married } & 166 & 92.74 & 518 & 96.64 & 684 & 95.66 \\ \text { Single/separated } & 13 & 7.26 & 18 & 3.36 & 31 & 4.34\end{array}$

\section{Religion}

\begin{tabular}{lllllll} 
Protestant & 159 & 88.83 & 492 & 91.79 & 651 & 91.05 \\
\hline Orthodox & 9 & 5.03 & 23 & 4.29 & 32 & 4.47 \\
\hline Catholic & 11 & 6.14 & 19 & 3.55 & 30 & 4.2 \\
\hline Others* & 0 & 0 & 2 & 0.37 & 2 & 0.28 \\
\hline Ethnicity & & & & & & \\
\hline Kembata & 140 & 78.21 & 470 & 87.69 & 610 & 85.31 \\
\hline Hadiya & 33 & 18.44 & 49 & 9.14 & 82 & 11.47 \\
\hline Others** & 6 & 3.35 & 17 & 3.17 & 23 & 3.22
\end{tabular}

\section{Educational status of the mothers}

\begin{tabular}{lcccccc}
$\begin{array}{l}\text { No formal } \\
\text { education }\end{array}$ & 47 & 26.26 & 64 & 11.94 & 111 & 15.52 \\
\hline $\begin{array}{l}\text { Primary } \\
\text { education }\end{array}$ & 122 & 68.15 & 376 & 70.15 & 498 & 69.65 \\
\hline Sec and above & 10 & 5.59 & 96 & 17.91 & 106 & 14.83 \\
\hline
\end{tabular}

\section{Educational status of the respondents' husband}

$\begin{array}{lllllll}\text { No formal } & 39 & 21.79 & 41 & 7.65 & 80 & 11.19\end{array}$
education

*= Seventh day Adventist and only Jesus **=Wolayita, Tembaro, Donga and Amhara 


\begin{tabular}{|c|c|c|c|c|c|c|}
\hline \multirow{2}{*}{$\begin{array}{l}\text { Characteristics } \\
\text { Primary } \\
\text { education }\end{array}$} & \multicolumn{2}{|c|}{$\begin{array}{l}\text { Pregnant mothers from } \\
\text { PSNP user HHs } n=179\end{array}$} & \multicolumn{2}{|c|}{$\begin{array}{l}\text { Pregnant mothers from non } \\
\text { PSNP user HHs } n=536\end{array}$} & \multicolumn{2}{|c|}{ Total $(n=715)$} \\
\hline & 114 & 63.68 & 343 & 63.99 & 457 & 63.91 \\
\hline Sec and above & 26 & 14.53 & 152 & 28.36 & 178 & 24.9 \\
\hline \multicolumn{7}{|c|}{ Maternal occupation } \\
\hline Gov't employee & 0 & 0 & 14 & 2.61 & 14 & 1.96 \\
\hline Housewife & 134 & 74.86 & 437 & 81.53 & 571 & 79.86 \\
\hline Farmer & 30 & 16.76 & 65 & 12.13 & 95 & 13.29 \\
\hline Merchant & 12 & 6.70 & 19 & 3.54 & 31 & 4.34 \\
\hline Private worker & 3 & 1.68 & 1 & 0.19 & 4 & 0.56 \\
\hline \multicolumn{7}{|c|}{ Husband occupation } \\
\hline Gov't employee & 1 & 0.56 & 23 & 4.29 & 24 & 3.36 \\
\hline Farmer & 79 & 44.13 & 192 & 35.83 & 271 & 37.9 \\
\hline Merchant & 30 & 16.76 & 98 & 18.28 & 128 & 17.9 \\
\hline Private worker & 48 & 26.82 & 171 & 31.9 & 219 & 30.63 \\
\hline Daily laborer & 21 & 11.73 & 52 & 9.7 & 73 & 10.21 \\
\hline \multicolumn{7}{|l|}{ Family size } \\
\hline$<2$ & 12 & 6.71 & 73 & 13.62 & 85 & 11.89 \\
\hline $3-4$ & 43 & 24.02 & 165 & 30.78 & 208 & 29.09 \\
\hline$>5$ & 124 & 69.27 & 298 & 55.6 & 422 & 59.02 \\
\hline \multicolumn{7}{|l|}{ Wealth index } \\
\hline Low income & 65 & 36.31 & 178 & 33.2 & 243 & 33.99 \\
\hline Middle income & 55 & 30.73 & 179 & 33.4 & 234 & 32.72 \\
\hline High income & 59 & 32.96 & 179 & 33.4 & 238 & 33.29 \\
\hline
\end{tabular}

Pregnancy related factors of the study participants

Nearly three quarter (73.74\%) of the respondents from PSNP user and 70.9\% from non PSNP user HHs were at third trimester during the data collection period. 150(83.8\%) respondents from PSNP user and 
427(79.7\%) from non PSNP user HHs had at least one ANC service during the current pregnancy (Table 2).

Table 2

Pregnancy related factors of the study participants in Kacha Birra District, 2019

\begin{tabular}{|c|c|c|c|c|c|c|}
\hline \multirow[t]{2}{*}{ Characteristics } & \multicolumn{2}{|c|}{$\begin{array}{l}\text { Pregnant mothers from } \\
\text { PSNP user HHs } n=179\end{array}$} & \multicolumn{2}{|c|}{$\begin{array}{l}\text { Pregnant mothers from } \\
\text { non PSNP user HHs } n= \\
536\end{array}$} & \multicolumn{2}{|c|}{ Total $n=715$} \\
\hline & frequency & percent & Frequency & Percent & frequency & Percent(\%) \\
\hline \multicolumn{7}{|c|}{ Previous pregnancy } \\
\hline$<2$ & 52 & 29.05 & 284 & 52.98 & 336 & 46.99 \\
\hline $3-4$ & 89 & 49.72 & 181 & 33.77 & 270 & 37.76 \\
\hline$>5$ & 38 & 21.23 & 71 & 13.25 & 109 & 15.25 \\
\hline \multicolumn{7}{|l|}{ Illnesses } \\
\hline Yes & 61 & 34.08 & 180 & 33.58 & 241 & 33.71 \\
\hline No & 118 & 65.92 & 356 & 66.42 & 474 & 66.29 \\
\hline \multicolumn{7}{|l|}{ ANC follow up } \\
\hline Yes & 150 & 83.8 & 427 & 79.66 & 577 & 80.7 \\
\hline No & 29 & 16.2 & 109 & 20.34 & 138 & 19.3 \\
\hline \multicolumn{7}{|l|}{ No of visit } \\
\hline Less than 4 & 146 & 97.33 & 415 & 97.19 & 561 & 97.23 \\
\hline Above 4 & 4 & 2.67 & 12 & 2.81 & 16 & 2.77 \\
\hline \multicolumn{7}{|c|}{ Trimester of the pregnancy } \\
\hline 1 & 1 & 0.56 & 12 & 2.24 & 13 & 1.82 \\
\hline 2 & 46 & 25.7 & 144 & 26.86 & 190 & 26.57 \\
\hline 3 & 132 & 73.74 & 380 & 70.9 & 512 & 71.61 \\
\hline
\end{tabular}

Exposure to nutrition information, Dietary knowledge and Attitude of the study participants

Among the non PSNP users, 297(55.4\%) had an information about nutrition during pregnancy whereas, 104(58.1\%) of participants from PSNP user HHs had information about nutrition. About $34 \%$ the respondents from non PSNP user HHs and 48(26.82\%) respondents from PSNP user HHs had good dietary knowledge. Also, 104(58.1\%) of the respondents from PSNP user households and $277(51.68 \%)$ of those from non PSNP user households had favorable attitude about dietary practice during pregnancy. 


\section{Dietary practice of the study participants}

The overall proportion of good dietary practice among the pregnant women in the district was $14.97 \%$ (95\%Cl: $12.3-17.6)$, whereas, it was $11.17 \%(95 \% \mathrm{Cl}: 6.5-15.8)$ and $16.23 \%(95 \% \mathrm{Cl}: 13.09-19.36)$ among pregnant women in PSNP user and non PSNP user households respectively Though the study indicated slight increase in the proportion of good dietary practice among pregnant women residing in non PSNP user households, the difference was not statistically significant by the Pearson chi square test $(p=0.1)$ (Fig. 1).

\section{Factors associated with the dietary practice of pregnant women in Kacha birra district}

In multivariable analysis, knowledge about diet, nutrition information and husband occupation were found to be significantly associated with the dietary practice of the pregnant women in the overall model at $p$ value $<0.05$.

Pregnant mothers who had good knowledge about diet during pregnancy were 2.64[AOR $=2.64$ (95\% $\mathrm{Cl}: 1.67-4.18)]$ times more likely to have good dietary practice than those who had poor knowledge. When compared to those who had no exposure to nutrition information, pregnant mothers who had exposure to nutrition information were $2.36[\mathrm{AOR}=2.36(95 \% \mathrm{Cl}: 1.41-3.95)]$ times more likely to have good dietary practice. Relative to the pregnant women whose husband was daily worker, the proportion of good dietary practice was $3.5[\mathrm{AOR}=3.51(95 \% \mathrm{Cl}: 1.02-12.08)]$ times higher among pregnant women whose husband was employed (Table 3) 
Table 3

Factors associated with the dietary practice of the pregnant women in Kacha birra district, 2019

\begin{tabular}{|c|c|c|c|c|c|c|}
\hline \multirow[t]{2}{*}{ Variable } & \multirow[t]{2}{*}{ Category } & \multicolumn{2}{|c|}{$\begin{array}{l}\text { Dietary } \\
\text { practice }\end{array}$} & \multirow[t]{2}{*}{ COR } & \multirow[t]{2}{*}{ AOR } & \multirow[t]{2}{*}{ p-value } \\
\hline & & Good & Poor & & & \\
\hline \multirow[t]{2}{*}{ Dietary knowledge } & $\begin{array}{l}\text { Poor } \\
\text { knowledge }\end{array}$ & 45 & 441 & 1 & 1 & \\
\hline & $\begin{array}{l}\text { Good } \\
\text { knowledge }\end{array}$ & 62 & 167 & $\begin{array}{l}3.64(2.38- \\
5.55)\end{array}$ & $\begin{array}{l}2.64(1.67- \\
4.18)\end{array}$ & $\hat{0.001 * *}$ \\
\hline \multirow[t]{3}{*}{ Previous pregnancy } & $\leq 2$ & 11 & 74 & 1 & 1 & \\
\hline & $3-4$ & 41 & 167 & $\begin{array}{l}0.72(0.46- \\
1.13)\end{array}$ & $\begin{array}{l}0.77(0.38- \\
1.55)\end{array}$ & 0.465 \\
\hline & $\geq 5$ & 55 & 367 & $\begin{array}{l}0.58(0.29- \\
1.12)\end{array}$ & $\begin{array}{l}0.57(0.23- \\
1.39)\end{array}$ & 0.218 \\
\hline \multirow[t]{3}{*}{ Family size } & $\leq 2$ & 59 & 277 & 1 & 1 & \\
\hline & $3-4$ & 36 & 234 & $\begin{array}{l}1.65(0.80- \\
3.39)\end{array}$ & $\begin{array}{l}1.85(0.85- \\
4.06)\end{array}$ & 0.122 \\
\hline & $\geq 5$ & 12 & 97 & $\begin{array}{l}1.01(0.50- \\
2.01)\end{array}$ & $\begin{array}{l}1.71(0.68- \\
4.32)\end{array}$ & 0.253 \\
\hline \multirow[t]{5}{*}{ Husband occupation } & $\begin{array}{l}\text { Gov't } \\
\text { employee }\end{array}$ & 10 & 14 & $\begin{array}{l}6.73(2.18- \\
20.74)\end{array}$ & $\begin{array}{l}3.51(1.02- \\
12.08)\end{array}$ & $0.047^{*}$ \\
\hline & Farmer & 40 & 231 & $\begin{array}{l}1.63(0.69- \\
3.18)\end{array}$ & $\begin{array}{l}1.46(0.61- \\
3.51)\end{array}$ & 0.396 \\
\hline & Merchant & 19 & 109 & $\begin{array}{l}1.64(0.65- \\
4.12)\end{array}$ & $\begin{array}{l}1.43(0.55- \\
3.75)\end{array}$ & 0.462 \\
\hline & Private worker & 31 & 188 & $\begin{array}{l}1.64(0.65- \\
3.69)\end{array}$ & $\begin{array}{l}1.55(0.63- \\
3.84)\end{array}$ & 0.339 \\
\hline & Daily laborer & 7 & 66 & 1 & 1 & \\
\hline \multirow[t]{2}{*}{ Nutrition Information } & Yes & 82 & 319 & $\begin{array}{l}2.97(1.85- \\
4.78)\end{array}$ & $\begin{array}{l}2.36(1.41- \\
3.95)\end{array}$ & $0.001 *$ \\
\hline & No & 25 & 289 & 1 & 1 & \\
\hline \multirow[t]{2}{*}{$\begin{array}{l}\text { Educational status of } \\
\text { the mother }\end{array}$} & $\begin{array}{l}\text { No formal } \\
\text { education }\end{array}$ & 15 & 96 & 1 & 1 & \\
\hline & $\begin{array}{l}\text { Primary } \\
\text { education }\end{array}$ & 63 & 435 & $\begin{array}{l}0.93(0.50- \\
1.69)\end{array}$ & $\begin{array}{l}0.77(0.40- \\
1.47)\end{array}$ & 0.430 \\
\hline
\end{tabular}

* = significant at $p$ value $<0.05 * *=$ strongly significant at $p$ value $<0.05$ 


\begin{tabular}{|lllllll|}
\hline Variable & Category & $\begin{array}{l}\text { Dietary } \\
\text { practice }\end{array}$ & COR & AOR & p-value \\
\hline & Sec and Above & 29 & 77 & $\begin{array}{l}2.41(1.21- \\
4.81)\end{array}$ & $\begin{array}{l}1.28(0.57- \\
2.90)\end{array}$ & 0.544 \\
\hline beneficiary status & PSNP user & 20 & 159 & 1 & 1 & \\
& Non PSNP & 87 & 449 & $\begin{array}{l}1.54(0.92- \\
2.59)\end{array}$ & $\begin{array}{l}1.28(0.73- \\
2.24)\end{array}$ & 0.383 \\
& user & & & & & \\
\hline *= significant at $p$ value $<0.05 * *=$ strongly significant at $p$ value $<0.05$ & & \\
\hline
\end{tabular}

\section{Discussion}

Mothers' sub optimal dietary practice during pregnancy negatively affects the growth of the fetus [3] and therefore predisposes to low birth weight, premature birth and prenatal mortality. It also adversely affects the health of the pregnant women [31].

This study showed that only $14.97 \%$ of the pregnant women had good dietary practice during pregnancy, which was lower than the results from Guto Gida district(33.9\%)[18], Bahir Dar city(39.3\%)[2], Gondar town(40.1\%)[15], Addis Ababa city(34.5\%)[19] and Ambo district(26.9\%) [17], Ethiopia. Also, it is lower than the results from different African and world countries: Nigeria(56.6\%)[3], Kenya(25.9\%)[20], Malaysia(74\%)[32] and Swaziland(51\%)[33]. The possible reason for this disparity may be low coverage of knowledge about maternal nutrition in the study area relative to that of from the above listed studies(for example, those studies in Gondar town[15], Bahir Dar[2], Malaysia[32] and Swaziland[33] have relatively high coverage of knowledge about maternal nutrition than that of the study area), variation in the residence and study setting (for example studies conducted in Addis Ababa[19], Kenya[20], Swaziland[33] and Nigeria[3]), while this study was conducted in rural setting and was community based) and dissimilarity in the sample size will also be an important determinant for the difference. Furthermore, the difference may also be due to the fact that the study area is chronically food insecure, while the above listed study areas are food secured.

This study also revealed the proportion of good dietary practice among pregnant mothers in PSNP user and non PSNP user households. Accordingly, $11.17 \%$ and $16.23 \%$ of the pregnant women residing in PSNP and non PSNP user households had good dietary practice respectively. Even though the study indicated that the proportion of good dietary practice among pregnant women residing in non PSNP user households was higher, the difference was not statistically significant $(p=0.1)$. The probable reason for the absence of statistically significant difference in the two groups may be due to subjectivity in inclusion of the HHs to the program so that those who should be included in the program may be left out. Moreover, the staple diet of the comparative groups was cereal based monotonous diet, resulting in low consumption of other food items on daily basis, rain dependent production of food items in all the selected kebeles and vulnerability to drought at the time of climate change can also be listed as factors 
that affect the presence of difference in the two groups. Furthermore, provision of targeted supplementary feeding (TSF) for pregnant mothers from the two groups whose MUAC is less than $23 \mathrm{~cm}$ at the stage of third trimester, not having big difference in the knowledge of the pregnant mothers about diet during pregnancy among the two groups and the small sample size from PSNP user households may mask the difference in the proportion of dietary practice in the two groups.

Concerning the determinant factors of dietary practice among the pregnant women, husband occupation was identified as a significant factor for the dietary practice of the pregnant mothers, which states that pregnant mothers whose husbands were employed had good dietary practice than those whose husbands were daily laborer, which is supported by evidences from Addis Ababa [19] and Ambo district[17]. It may be because of those employed husbands have relatively better educational status and knowledge level than the daily laborers, which may contribute a lot in giving information about the importance of having good dietary practice during pregnancy and increase a tendency to practice it. Also, those employed husbands have good income status so that able to purchase different kinds of food for the household and also may have relatively better support to their pregnant wives to have a healthy dietary practices than daily laborers.

In addition, nutrition information during pregnancy showed significant statistical association with the dietary practice among pregnant mothers, explaining that mothers having nutrition information had better dietary practice than those who had no exposure to nutrition information during their current pregnancy. Similar findings had also been reported from a study in Ogun state, Nigeria [34]Gondar [15] Guto gida[18]and Ambo district [17], Dessie[14] and Addis Ababa[35], elucidating strong statistical association between nutrition information and dietary practice. This might be due to the fact that, exposure to nutrition information can bring improvement in the level of knowledge and understanding, which in turn influences the dietary practice of the pregnant mothers positively. Moreover, the study participants' knowledge about diet during pregnancy showed significant association with their dietary practice. Pregnant mothers having good knowledge about diet during pregnancy had good dietary practice than those who had poor knowledge. This finding is similar with that of from Swaziland [33], Malaysia [32], Gondar [15], Bahir Dar [2] and Addis Ababa [19]. This may be due to the fact that improvement in the level of knowledge about diet during pregnancy positively influences the dietary attitude then the dietary practice of the mother indirectly [33] and the dietary practice directly[36]. Also, those mothers who have good knowledge about maternal nutrition during pregnancy have high probability to be employed so that they have good income to purchase different kind of food items for the household.

\section{Strength and limitation of the study}

This study tried to compare the proportion of good dietary practice among pregnant women in PSNP user and non PSNP user households by using comparative cross-sectional study design, which can be considered as the strength of the study. However, some of the limitations ought to be taken into account while interpreting the results. The study is not free from social desirability bias while measuring the 
dietary practice of the pregnant women. Factors like: presence of chronic illnesses were not investigated by the study. Finally, only quantitative type of data was explored by the study.

\section{Conclusion}

This study illustrated low proportion of good dietary practice among pregnant women in Kacha Birra District. Moreover, the proportion of good dietary practice had no statistically significant difference between pregnant women residing in PSNP user and non PSNP user households. Factors like: nutrition information, dietary knowledge and husband occupation showed significant association with the dietary practice of the pregnant women. Therefore, giving due attention to the improvement of knowledge of the pregnant mothers about nutrition during pregnancy through nutrition education and enhancing their exposure to nutrition information is recommended. Moreover, it is better to strengthen the already existing program to support pregnant mothers. Also, it is good if further investigation by using qualitative method is done to extract more information about the dietary practice and associated factors.

\section{Abbreviations}

ANC: Antenatal Care, AOR: Adjusted Odds Ratio, Cl: Confidence Interval, COR: Crude Odds Ratio, HHs: Households, PCA: Principal Component Analysis, PSNP: Productive Safety Net Program, SNNPR: South Nations and Nationalities People Region, SRS: Simple Random Sampling, TSF: Targeted Supplementary Feeding, WHO: World Health Organization

\section{Declarations}

\section{Ethical approval and consent to participate}

Ethical clearance was obtained from the Ethical Review Committee of the Institute of Public Health, the University of Gondar. Also, official permission letter was obtained from Kacha Birra District administrative and health offices after detail explanation of the purpose of the study. The objective of the study was briefly clarified and informed consent was obtained from the pregnant women as all of them participated in the study were aged above eighteen. Any risk on participants during data collection was minimized and name or any other identifying information of the pregnant women was not recorded on the questionnaire and all information was kept strictly confidential. The information retrieved was only used for the study purpose. It was informed that participants who are unwilling to participate on the study have the right to quit at any time.

\section{Consent for publication}

Not applicable

\section{Availability of data and material}


The datasets used and / or analyzed during the current study are available from the corresponding author on reasonable request.

\section{Competing interest}

The authors declare that there is no any competing interest.

\section{Funding}

The authors have declared that there was no funding.

\section{Authors' contributions}

LDB wrote the proposal, involved in the study design, analyzed the data, and drafted the paper. TD and EAM approved the design, the proposal, involved in the data analysis, revised subsequent drafts of the paper and reviewing the manuscript. All authors read and approved the final manuscript.

\section{Acknowledgements}

We would like to acknowledge the University of Gondar for the ethical clearance. The authors would like to thank the study participants, data collectors and the supervisors.

\section{References}

1. Chitsaz, A., et al., The Predictors of Healthy Eating Behavior among Pregnant Women: An Application of the Theory of Planned Behavior. International Journal of Pediatrics, 2017. 5(10): p. 5897-5905.

2. Nana, A. and T. Zema, Dietary practices and associated factors during pregnancy in northwestern Ethiopia. BMC pregnancy and childbirth, 2018. 18(1): p. 183.

3. Oyindamola, O., Factors influencing dietary practices among pregnant women in Adeoyo Maternity Hospital, Yemetu, Ibadan, Oyo State.

4. Neggers, Y., Epidemiology of Malnutrition: Maternal and Child Malnutrition. Journal of Gynecology and Neonatal Biology, 2016. 2(2): p. 0-0.

5. Organization, W.H., Multiple micronutrient supplements in pregnancy: implementation considerations for successful integration into existing programmes. 2015.

6. UNICEF, Micronutrients. 2018.

7. Ahmed, T., M. Hossain, and K.I. Sanin, Global burden of maternal and child undernutrition and micronutrient deficiencies. Annals of Nutrition and Metabolism, 2012. 61(Suppl. 1): p. 8-17.

8. Lartey, A., Maternal and child nutrition in Sub-Saharan Africa: challenges and interventions. Proc Nutr Soc, 2008. 67(1): p. 105-8.

9. agency, C.s., Ethiopia demographic health survey 2016. 
10. Kassa, G.M., et al., Prevalence and determinants of anemia among pregnant women in Ethiopia; a systematic review and meta-analysis. BMC hematology, 2017. 17(1): p. 17.

11. Tafese, Z. and A. Kebebu, A Systematic Review of Maternal Feeding Practice and its Outcome in Developing Countries. J NursWomens Health, 2017. 2017: p. J119.

12. Bezabih, A., et al., Demand and Supply Side Barriers that Limit the Uptake of Nutrition Services among Pregnant Women from Rural Ethiopia: An Exploratory Qualitative Study. Nutrients, 2018. 10(11): p. 1687.

13. Castrogiovanni, P. and R. Imbesi, The Role of Malnutrition during Pregnancy and Its Effects on Brain and Skeletal Muscle Postnatal Development. Journal of Functional Morphology and Kinesiology, 2017. 2(3): p. 30.

14. Diddana, T.Z., et al., Effect of Nutrition Education Based on Health Belief Model on Nutritional Knowledge and Dietary Practice of Pregnant Women in Dessie Town, Northeast Ethiopia: A Cluster Randomized Control Trial. Journal of Nutrition and Metabolism, 2018. 2018.

15. Alemayehu, M.S. and E.M. Tesema, Dietary practice and associated factors among pregnant women in Gondar town north west, Ethiopia, 2014. Int J Nutr Food Sci, 2015. 4(6): p. 707-12.

16. Ethiopia, G.o.F.D.R.o., national nutrition program 2013-2015. 2013.

17. Tolera, B., S. Mideksa, and N. Dida, ASSESSMENT OF DIETARY PRACTICE AND ASSOCIATED FACTORS AMONG PREGNANT MOTHER IN AMBO DISTRICT, WEST SHOA, OROMIA, ETHIOPIA, 2018. Ethiopian Journal of Reproductive Health, 2018. 10(4).

18. Daba, G., et al., Assessment of nutritional practices of pregnant mothers on maternal nutrition and associated factors in Guto Gida Woreda, east Wollega zone, Ethiopia. Science, Technology and Arts Research Journal, 2013. 2(3): p. 105-113.

19. Tenaw, Z., M. Arega, and E. Tachbele, Nutritional knowledge, attitude and practices among pregnant women who attend antenatal care at public hospitals of Addis Ababa, Ethiopia. International Journal of Nursing and Midwifery, 2018. 10(7): p. 81-89.

20. Perumal, N., et al., Health and nutrition knowledge, attitudes and practices of pregnant women attending and not-attending ANC clinics in Western Kenya: a cross-sectional analysis. BMC pregnancy and childbirth, 2013. 13(1): p. 146.

21. Organization., W.H., Nutrition: nutrition of women in the preconception period, during pregnancy and the breastfeeding period. . World Health Assembly, 2012). 65.

22. Handiso, Y.H., Prevalence of food aversions, cravings and pica during pregnancy and their association with nutritional status of pregnant women in Dale Woreda, Sidama zone, SNNPRS, Ethiopia. International Journal of Nutrition and Metabolism, 2015. 7(1): p. 1-14.

23. Ethiopia, G.o.F.D.R.o., National Nutrition Program 2016-2020. 2016.

24. Programme, W.F., Productive Safety Net Program. 2012.

25. Berhane, G., et al., The Productive Safety Net Programme in Ethiopia Impacts on children's schooling, labour and nutritional status: impact evaluation report. 2017. 
26. Kacha birra district Adminstrative office annual report. 2018.

27. Kachabirra district Adminstrative office, disaster and risk management office, early warning and response cluster. 2018.

28. Daba, G., et al., Assessment of knowledge of pregnant mothers on maternal nutrition and associated factors in Guto Gida Woreda, East Wollega Zone, Ethiopia. Journal of Nutrition \& Food Sciences, 2013. 3(6): p. 1.

29. Bookari, K., H. Yeatman, and M. Williamson, Informing nutrition Care in the Antenatal Period: pregnant Women's experiences and need for support. BioMed research international, 2017. 2017.

30. Vyas, S. and L. Kumaranayake, Constructing socio-economic status indices: how to use principal components analysis. Health policy and planning, 2006. 21(6): p. 459-468.

31. Ahmed, F. and M. Tseng, Diet and nutritional status during pregnancy. Public health nutrition, 2013. 16(8): p. 1337-1339.

32. Mirsanjari, M., et al., Does nutritional knowledge have relationship with healthy dietary attitude and practices during pregnancy. ICNFS, 2012. 39: p. 159-163.

33. Masuku, S.K. and S.-J.J. Lan, Nutritional knowledge, attitude, and practices among pregnant and lactating women living with HIV in the Manzini region of Swaziland. Journal of health, population, and nutrition, 2014. 32(2): p. 261.

34. Ogechi, A.C. and O.O. Hamdalat, Factors Influencing the Nutritional Practice of Pregnant Women Living in a Semi-Urban Region of Ogun State, Nigeria. Religion. 10(76.4): p. 5.3.

35. Zelalem, A., et al., Effect of nutrition education on pregnancy specific nutrition knowledge and healthy dietary practice among pregnant women in Addis Ababa. Clinics in Mother and Child Health, 2017. 14(3): p. 265.

36. SAEIDLOU, S.N., F. BABAEI, and P. AYREMLOU, Nutritional knowledge, attitude and practice of north west households in Iran: is knowledge likely to become practice? Maedica, 2016. 11(4): p. 286.

\section{Figures}




\section{Dietary practice of the respondents}



Figure 1

Proportion of dietary practice among the pregnant women in Kacha birra district, 2019 